\title{
Cocaine, $d$-Amphetamine, and Pentobarbital Effects on Responding Maintained by Food or Cocaine in Rhesus Monkeys
}

\author{
Seymore Herling *, David A. Downs **, and James H. Woods \\ Departments of Psychology and Pharmacology, University of Michigan, Ann Arbor, MI 48109, U.S.A.
}

\begin{abstract}
The effects of IM injections of cocaine, $d$-amphetamine, and pentobarbital were studied in rhesus monkeys whose lever-press responding was maintained under a second-order fixed-interval, fixed ratio schedule of reinforcement. Within each session, fixed-interval components, ending with the IV injection of $30 \mu \mathrm{g} / \mathrm{kg}$ cocaine (one group of monkeys) or the delivery of a $300 \mathrm{mg}$ food pellet (second group of monkeys), alternated with fixed-interval components ending without an injection of cocaine or the delivery of food (extinction). Drug pretreatments generally caused comparable dose-related decreases in the overall rates of responding reinforced either by cocaine or by food. Response rates during extinction usually increased and then decreased as the dose of each drug increased. An analysis of the drug effects on response rates in different temporal segments of the fixed intervals showed that in both the reinforcement and extinction components, the normally low control rates of responding which occurred earlier in the intervals were usually increased, while higher control rates which occurred later in the intervals were increased less or decreased. Thus, the effects of these drugs were relatively independent of the reinforcing event (food or cocaine) and tended to depend more on the ongoing rate of responding under these conditions.
\end{abstract}

Key words: Cocaine - Second-order schedules $d$-Amphetamine - Rate-dependent - Pentobarbital

- Rhesus monkeys - Self-administration

The effects of drugs on behavior maintained by IV injections of psychomotor stimulants have been studied

* To whom offprint requests should be sent

** Present address: Pharmacology Department, Warner Lambert/Parke-Davis Pharmaceutical Research Division, 2800 Plymouth Road, Ann. Arbor, MI 48105, U.S.A. by several investigators in a variety of animal species, including rats (Pickens et al., 1968; Davis and Smith, 1972; Yokel and Wise, 1976), squirrel monkeys (Goldberg and Gonzalez, 1976; Gill et al., 1978), and rhesus monkeys (Wilson and Schuster, 1972, 1973). Wilson and Schuster (1972) have, for example, shown that in rhesus monkeys, chlorpromazine increases responding maintained by injections of cocaine, whereas $d$-amphetamine produces a dose-related decrease in cocaine-reinforced responding (Wilson and Schuster, 1973). Such changes in psychomotor stimulant-reinforced responding are often interpreted in terms of changes produced in the reinforcing effect of the drug reinforcer by the pretreatment agents (e.g., Wilson and Schuster, 1972, 1973; Yokel and Wise, 1976; Gill et al., 1978).

Although rarely used, an appropriate experimental context for such evaluations would allow drug effects on drug-reinforced responding to be compared with effects of drugs on behavior maintained by nondrug reinforcers. In many of the experiments cited above, drug effects on drug-reinforced responding were studied in the absence of a direct comparison with other reinforcers. In addition, the direction and magnitude of the behavioral effects of many drugs depend upon ongoing rates and patterns of operant behavior (e.g., Kelleher and Morse, 1968). It would be surprising if drug-reinforced operant behavior were an exception to this rule. Whether drug pretreatments increase or decrease responding maintained by psychomotor stimulants may depend on the rate and pattern of responding maintained by the drug reinforcer, as well as on some pharmacological interaction between the pretreatment drug and the drug reinforcer.

Finally, several examples in the literature suggest that drugs may or may not affect behavior differently when responding is maintained by different reinforcing stimuli (McKearney and Barrett, 1978). In the one experiment in which the effects of a drug were compa- 
red on responding reinforced by food and cocaine, propranolol, at doses that had no effect on foodreinford responding, decreased comparable rates of cocaine-maintained behavior by approximately $30 \%$ (Goldberg and Gonzalez, 1976). This finding suggested that propranolol potentiated the direct effects of IV self-administered cocaine, since increasing the injection dose of cocaine also decreased drug-maintained responding (Goldberg and Gonzalez, 1976).

The purpose of the present experiment was to investigate the effects of cocaine, $d$-amphetamine, and pentobarbital, drugs shown to have effects that depend on the ongoing rate of responding maintained by nondrug reinforcers in several species (Kelleher and Morse, 1968), in a situation in which food presentations and IV injections of cocaine maintained comparable rates and patterns of behavior in rhesus monkeys.

The present experiment used a second-order fixedinterval, fixed-ratio schedule of reinforcement. A fixedinterval (FI) schedule characteristically produces a wide range of response rates within the FI and allows an examination of the contribution of these rates of responding in determining the magnitude and direction of a drug's effect on operant behavior. A second-order FI, fixed-ratio (FR) schedule of reinforcement was used in an attempt to generate comparable rates and patterns of responding across individual monkeys (Goldberg, 1973). In addition, within each daily session, responding under one stimulus condition was reinforced while under a second stimulus condition, reinforcement was withheld (extinction). Comparable control rates of responding maintained by the two different reinforcers and rates of responding in extinction were used to assess the rate-dependent effects of cocaine, $d$-amphetamine, and pentobarbital on responding maintained by food or cocaine reinforcement, and responding in extinction.

\section{Materials and Methods}

Animals. Six rhesus monkeys (Macaca mulatta) weighing $4.4-6.5 \mathrm{~kg}$ at the start of the experiment served as experimental subjects. Five of the monkeys had histories of lever pressing maintained by food or drug, while the sixth (709) was experimentally naive. Three of the monkeys $(621,641$, and 594) were maintained at approximately $80 \%$ of their free-feeding weights and were trained to respond for food. These monkeys had free access to water in their home cages and were fed sufficient Purina Monkey Chow after each daily session to maintain their reduced weights. The food was treated by the manufacturer with $608.3 \mathrm{~g}$ isoniazid $/ 907 \mathrm{~kg}$ food.

Three other monkeys $(643,667$, and 709) were prepared surgically with siliconized rubber catheters (Rodhelm Reiss, Inc., Belle Mead, NJ) (outer diam $0.24 \mathrm{~cm}$, inner diam $0.08 \mathrm{~cm}$ ) in the right or left internal jugular or femoral veins. The distal end of the catheter was passed SC to the monkey's back where it exited from the midscapular area. A leather vest was worn by each monkey to protect the catheter. These monkeys were trained to respond for IV injections of cocaine.
They had free access to water in their home cages and were fed ten food biscuits twice daily.

Apparatus. Before each daily session, the monkeys were removed from their individual home cages and placed in restraint chairs. Each monkey was then placed in a sound-attenuating chamber containing a response lever (BRS/LVE, model PRL-001/121-07) and various colored stimulus lights (General Electric Co., model C7-CC). A food pellet dispenser (Ralph Gerbrands Co., model A) mounted outside the chamber delivered $300 \mathrm{mg}$ food pellets (Noyes, banana flavored) to a metal cup mounted on the lever panel. A motor-driven syringe (Sage Instruments, Inc., model 249-2) located outside the chamber was connected to the catheters of those monkeys whose responding was maintained by IV injections of cocaine. White noise was present in the chamber at all times. Lever-press responding was maintained either by $300 \mathrm{mg}$ banana-flavored food pellets (food-reinforced monkeys) or 15 -s injections of $30 \mu \mathrm{g} / \mathrm{kg} /$ injection of cocaine hydrochloride dissolved in $0.5 \mathrm{cc}$ of $0.9 \%$ sterile saline solution (cocainereinforced monkeys). A dose of $30 \mu \mathrm{g} / \mathrm{kg}$ was chosen because in preliminary observations this dose of cocaine did not have response limiting effects under the schedule of reinforcement used in the present experiment. Higher doses of cocaine tend to maintain lower response rates and disrupt the pattern of responding (Herling and Woods, unpublished data).

Procedure. In the presence of one set of colored stimulus lights, responding was maintained under a second-order 5-min FI, ten response FR schedule of reinforcement [FI 5 (FR 10:S)]. The schedule designation is that used by Kelleher (1966). During the 5-min FI (FI 5), every tenth response (FR 10) produced a 0.5 - s flash of a second colored stimulus light $\left(S_{1}\right)$. During the presentation of $S_{1}$, the lights signalling the FI were turned off. The first FR 10 completed after $5 \mathrm{~min}$ had elapsed, resulted in either the 0.5 -s flash of $\mathrm{S}_{1}$ and a single $300 \mathrm{mg}$ banana-flavored food pellet [FI 5 (FR 10: $\mathrm{S}_{1}$ ) food] or a 15-s presentation of $S_{1}$ and a $15-\mathrm{s}$ IV injection of $30 \mu \mathrm{g} / \mathrm{kg}$ cocaine [FI 5 (FR 10: $S_{1}$ ) cocaine].

In the presence of a different set of colored lights, reinforcement was withheld (extinction component). In this component of the schedule each FR 10 produced a 0.5 -s flash of a stimulus light $\left(\mathrm{S}_{2}\right)$ but the first FR 10 completed after $5 \mathrm{~min}$ was not reinforced [FI 5 (FR 10: $\mathrm{S}_{2}$ ) extinction]. During $\mathrm{S}_{2}$, the stimulus lights which signalled the extinction component were turned off. The reinforcement and extinction components of this multiple schedule alternated. A 30 -s time-out period during which the chamber was unlighted followed each FI 5 component. If an FR 10 was not completed within 1 min after the FI 5 had elapsed, the FI was terminated (1-min limited hold), and the 30-s time out period went into effect. Each daily session consisted of $20 \mathrm{FI}$ components and lasted approximately $2 \mathrm{~h}$.

When responding under this multiple second-order schedule appeared to be stable (at least five consecutive sessions during which there was no consistent upward or downward trend in response rates), the effects of IM pretreatments with cocaine, $d$-amphetamine, pentobarbital, and appropriate vehicles were evaluated. Drug injections were not given more often than once every fourth session and were administered in an unsystematic dose sequence. In most cases, at least two observations were obtained at each dose. Injections of comparable volumes of the appropriate vehicles were given intermittently throughout the experiment. At least 1 day in which no injection was given intervened between a vehicle injection and a drug pretreatment. The drugs were given immediately prior to the experimental session in a volume of $0.5 \mathrm{ml} / \mathrm{kg}$ body weight.

Overall response rates and average rates of responding during consecutive $30-\mathrm{s}$ segments of each FI component (local response rates) were computed from elapsed timers and response counters.

Drugs. The drugs were studied in the following order : Cocaine; $d$-amphetamine; and pentobarbital. At least 1 week intervened between 
the end of a series of pretreatments with one drug and the start of a series of pretreatments with another. Cocaine hydrochloride and $d$-amphetamine sulfate were dissolved in $0.9 \%$ sodium chloride solution. A solution of $20 \%$ propylene glycol, $10 \%$ ethyl alcohol, and $70 \%$ distilled water was the injection vehicle for sodium pentobarbital. Dose refers to the salt of each drug.

\section{Results}

Control Performance. During sessions in which no drug pretreatment was given, each monkey exhibited a higher mean rate of responding during the reinforcement component than during the extinction component of the schedule (Table 1 ).

In general, the overall patterns of responding in the reinforcement components of the schedule resembled the patterns of responding that have previously been reported for second-order FI schedules of cocaine injection and food presentation (Goldberg, 1973; Woods et al., 1978); that is, low rates of responding occurred during the initial portions of the interval and higher response rates occurred toward the end. In addition, pauses in responding that preceded and followed the completion of each FR 10 unit in the reinforcement components were generally longest at the beginning of the interval and became shorter as the interval progressed in time. These response patterns were also seen in the extinction components of the schedule, although the rates of responding were considerably lower and the limited-hold contingency of 1 min was occasionally met.

Drug Effects on the Overall Rate of Responding. The effects of cocaine, $d$-amphetamine, and pentobarbital on the mean rate of responding, expressed as a percentage of the control rate, are shown in Fig. 1. The lowest doses of cocaine $(0.1-1.0 \mathrm{mg} / \mathrm{kg})$ and $d$-amphetamine $(0.03-0.1 \mathrm{mg} / \mathrm{kg})$ had little or no effect on the overall rate of reinforced responding, whether food or cocaine served to maintain behavior. Higher doses of

Table 1. Mean control response rates (responses/s) for individual monkeys whose responding was maintained either by food or cocaine $^{\mathrm{a}}$

\begin{tabular}{llll}
\hline & & $\begin{array}{l}\text { Reinforcement } \\
\text { component }\end{array}$ & $\begin{array}{l}\text { Extinction } \\
\text { component }\end{array}$ \\
\hline Food & 621 & $0.69 \pm 0.02^{b}$ & $0.14 \pm 0.02$ \\
monkeys & 594 & $0.26 \pm 0.02$ & $0.14 \pm 0.01$ \\
& 641 & $1.05 \pm 0.05$ & $0.46 \pm 0.02$ \\
Cocaine & 643 & $1.46 \pm 0.08$ & $0.27 \pm 0.04$ \\
monkeys & 709 & $0.68 \pm 0.03$ & $0.04 \pm 0.01$ \\
& 667 & $0.58 \pm 0.03$ & $0.03 \pm 0.01$
\end{tabular}

\footnotetext{
${ }^{a}$ Based on the five noninjection control days that preceded the start of each series of drug pretreatments

${ }^{\mathrm{b}}$ The entries following the averages indicate \pm 1 SEM $(N=15)$
}

these two drugs produced dose-related rate decreases in the reinforcement component in all monkeys. While the lowest dose of pentobarbital had little effect on behavior, an intermediate dose of the drug $(5.6 \mathrm{mg} / \mathrm{kg})$ increased reinforced responding slightly. Response rates were suppressed only at the highest dose of pentobarbital. In general, each drug had an overall effect on response rate that was similar for responding reinforced by either food or cocaine.

In the extinction component of the schedule, each drug increased the rate of responding at doses that had
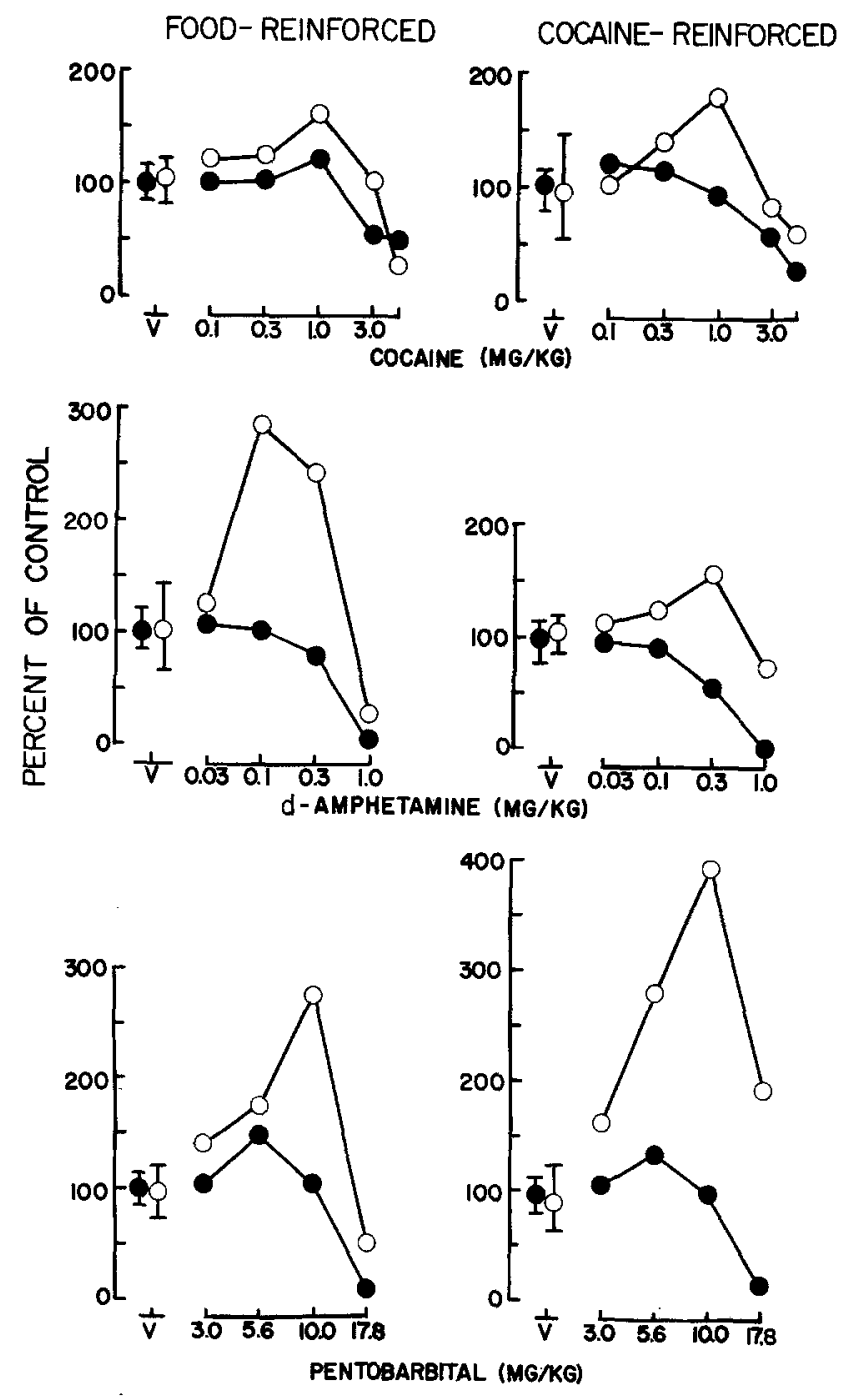

Fig. 1. Effects of cocaine, $d$-amphetamine, and pentobarbital on reinforced and extinguished responding in three food-reinforced monkeys and three cocaine-reinforced monkeys: Abscissas $=$ dose, $\log$ scale; ordinates $=$ rate of responding as a percentage of the mean rate of responding on five noninjection control sessions preceding the start of drug pretreatments. The brackets at $V$ represent the range of responding on at least five sessions in which a vehicle was given. Filled circles represent reinforced responding and open circles represent extinguished responding. In most instances each point is the mean of at least two observations in each of three monkeys 


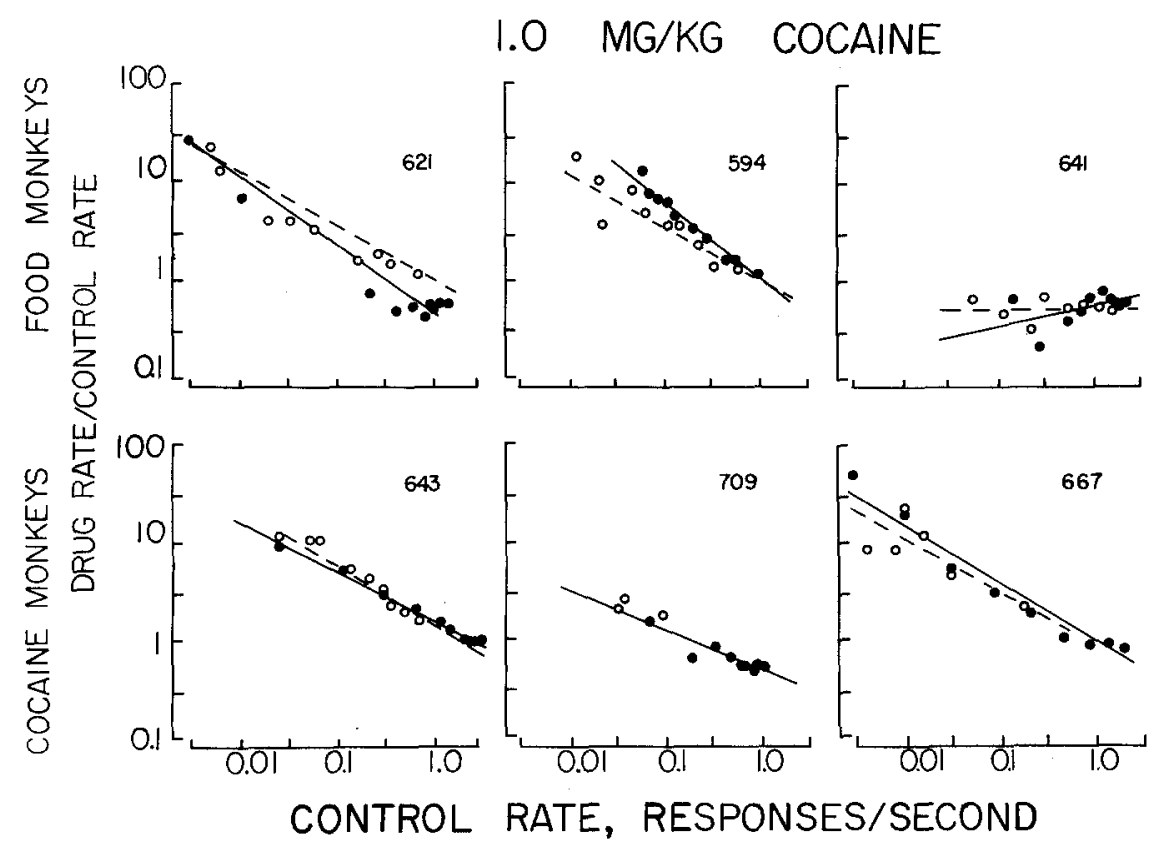

Fig. 2. Effects of $1.0 \mathrm{mg} / \mathrm{kg}$ cocaine (im) on reinforced and extinguished responding as a function of predrug (control) response rates for monkeys whose responding was maintained either by food (top row) or cocaine (bottom row): Abscissas = mean rate of responding during individual 30 -s segments of the FI; ordinates = rate of responding after drug pretreatment as a ratio of the mean control rate. Points were not plotted if control rates were less than 0.001 responses, or if the pretreatment decreased the post-injection rate to less than $1 \%$ of the control rate. Each point is the mean of at least two observations. Filled circles represent reinforced responding and open circles represent responding during extinction. Lines were fitted to the points by the method of least-squares. Solid regression lines denote reinforced responding. Dashed regression lines show responding in extinction

little or no effect on reinforced responding. The maximum response rate increases produced by pentobarbital in the extinction component tended to be as large or larger than those caused by the other two drugs. Drug-induced increases in response rate during extinction occurred whether food or cocaine served to maintain responding in the reinforcement component of the schedule.

Inspection of cumulative response records revealed that cocaine pretreatments produced a dose-related suppression of responding at the beginning of the session. When responding resumed, it did so at rates higher than those observed under control conditions. Response rate increases were particularly evident in those portions of the session in which low rates of responding normally occurred, i.e., the initial portions of the FI in which responding was reinforced and throughout most of the extinction components.

$d$-Amphetamine and pentobarbital produced effects in the FI that were qualitatively similar to those produced by presession injections of cocaine. That is, both $d$-amphetamine and pentobarbital produced the greatest increases in response rates in those portions of the intervals during which low rates of responding occurred. However, neither $d$-amphetamine nor pen- tobarbital caused the complete suppression of responding at the beginning of the session seen with cocaine. In addition, at doses that produced the most pronounced overall response rate increases, the rate-enhancing effects of $d$-amphetamine and pentobarbital tended to be longer lasting than those of cocaine.

Drug Effects on Responding Within Consecutive 30-s Segments of Fixed Intervals. Figures 2, 3, and 4 compare the effects of cocaine $(1.0 \mathrm{mg} / \mathrm{kg}), d$-amphetamine $(0.3 \mathrm{mg} / \mathrm{kg})$, and pentobarbital $(10 \mathrm{mg} / \mathrm{kg})$ on the rate of responding in 30-s segments (local response rates) of the FI as a function of the control rate of responding in the three food-reinforced monkeys and in the three cocaine-reinforced monkeys. These doses of the drugs tended to produce the largest increases in response rates. In most instances, the drugs increased low control rates of responding at doses that had little effect on or decreased higher control rates. For example, in two food-maintained monkeys (594 and 621) low control rates of responding were elevated by $1.0 \mathrm{mg} / \mathrm{kg}$ cocaine, while higher rates were increased less or decreased (Fig. 2); this effect was similar whether responding was reinforced (closed circles) or extinguished (open circles). Monkey 641, the third food-maintained monkey, 


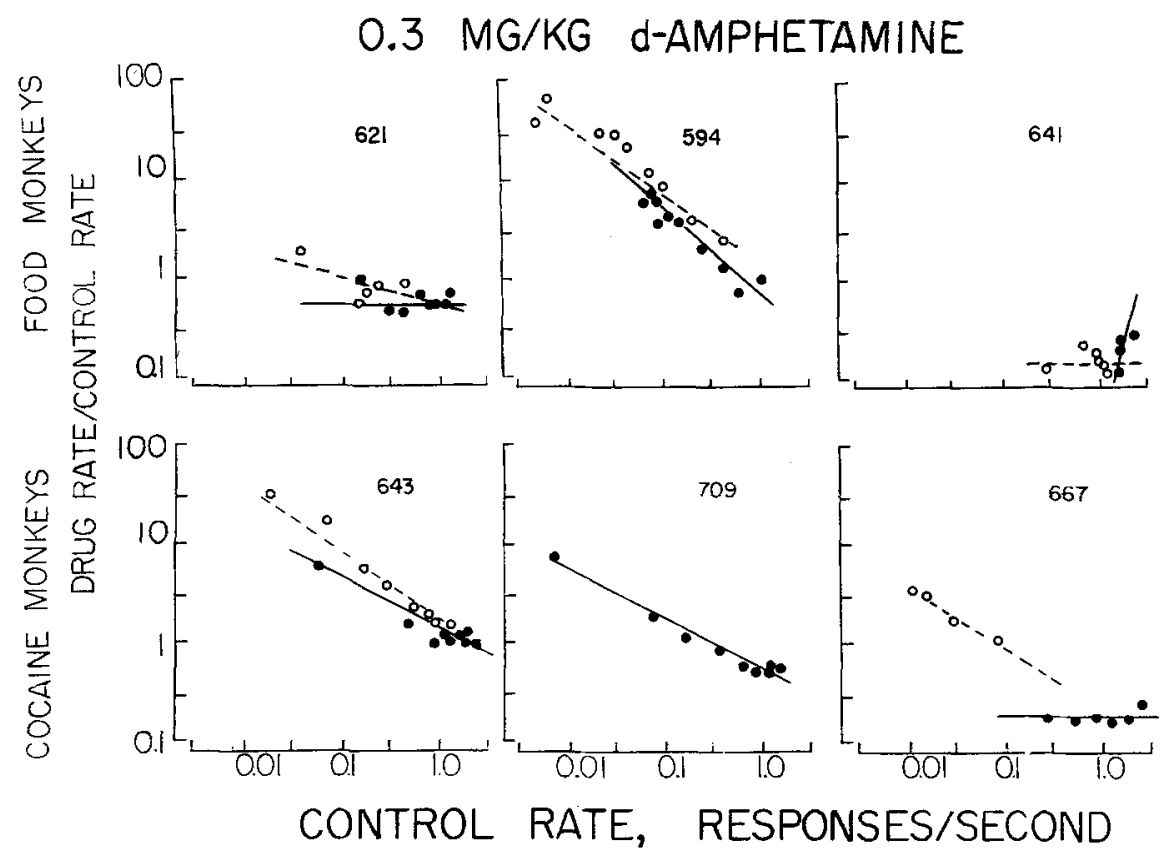

Fig. 3. Effects of $0.3 \mathrm{mg} / \mathrm{kg} d$-amphetamine (im) on reinforced and extinguished responding as a function of predrug (control) response rates for monkeys whose responding was maintained either by food (top row) or cocaine (bottom row). Refer to Fig. 2 for further details

had predominantly high local control rates of responding under both components of the schedule and showed only rate decreases following cocaine pretreatment.

In two cocaine-reinforced monkeys (667 and 643) $1.0 \mathrm{mg} / \mathrm{kg}$ cocaine produced marked increases in low rates of responding; higher control response rates were increased less or decreased in both the reinforcement and the extinction components of the schedule. Monkey 709 responded in only a small portion of the 30-s segments of the FI during extinction and these response rates were elevated slightly by cocaine, while the majority of the higher local rates of reinforced responding in this animal were unaffected or decreased.

In general, $d$-amphetamine $(0.3 \mathrm{mg} / \mathrm{kg})$ produced effects on local rates that were similar for reinforced and extinguished responding (Fig. 3). Comparable increases of low rates in both components of the schedule, however, were evident only for monkeys 594 (foodmaintained) and 643 (cocaine-maintained). In contrast, $d$-amphetamine eliminated the low rates of responding in extinction for monkey 709, and completely suppressed the low rates of responding in both components for monkey 641 while decreasing higher response rates less.

Pentobarbital $(10 \mathrm{mg} / \mathrm{kg})$, compared to cocaine and $d$-amphetamine, caused the most consistent ratedependent changes in local response rates in all monkeys. In addition, the effects of pentobarbital were virtually identical whether food or cocaine served as the reinforcer, and both reinforced and extinguished responding were affected similarly (Fig. 4).

The rate-dependent effects of drugs can be summarized on the basis of slopes and intercepts of the regression lines that are fitted to data such as those in Fig. 2, 3, and 4 (McMillan, 1973; Leander, 1975; Harris et al., 1978). Pentobarbital produced the strongest rateand dose-dependent effects of the three drugs studied (Table 2). As the dose of pentobarbital increased the slopes of the regression lines became more negative. In addition, the $y$ value of the regression lines (i.e., the rate of responding after drug injection), when the $x$ value (i.e., the control rate) was one response/s, was increased by pentobarbital at intermediate doses and decreased only at the highest dose. On the other hand, cocaine increased the negative slope of the regression lines at doses that generally decreased the $y$ value, when the $x$ value was one response/s. Since high control rates of responding (one response/s) were decreased by cocaine $(1.0-5.6 \mathrm{mg} / \mathrm{kg})$ and either increased or left unchanged by pentobarbital $(3.2-10.0 \mathrm{mg} / \mathrm{kg}$ ) at doses that produced substantial rate-dependent effects, pentobarbital tended to produce greater overall response-rate increases than cocaine. These effects were similar whether responding was reinforced by food or cocaine. The consistency of the rate-dependent effects of these two drugs is indicated by the values of the correlation coefficients, which in most instances were above 0.8 . 


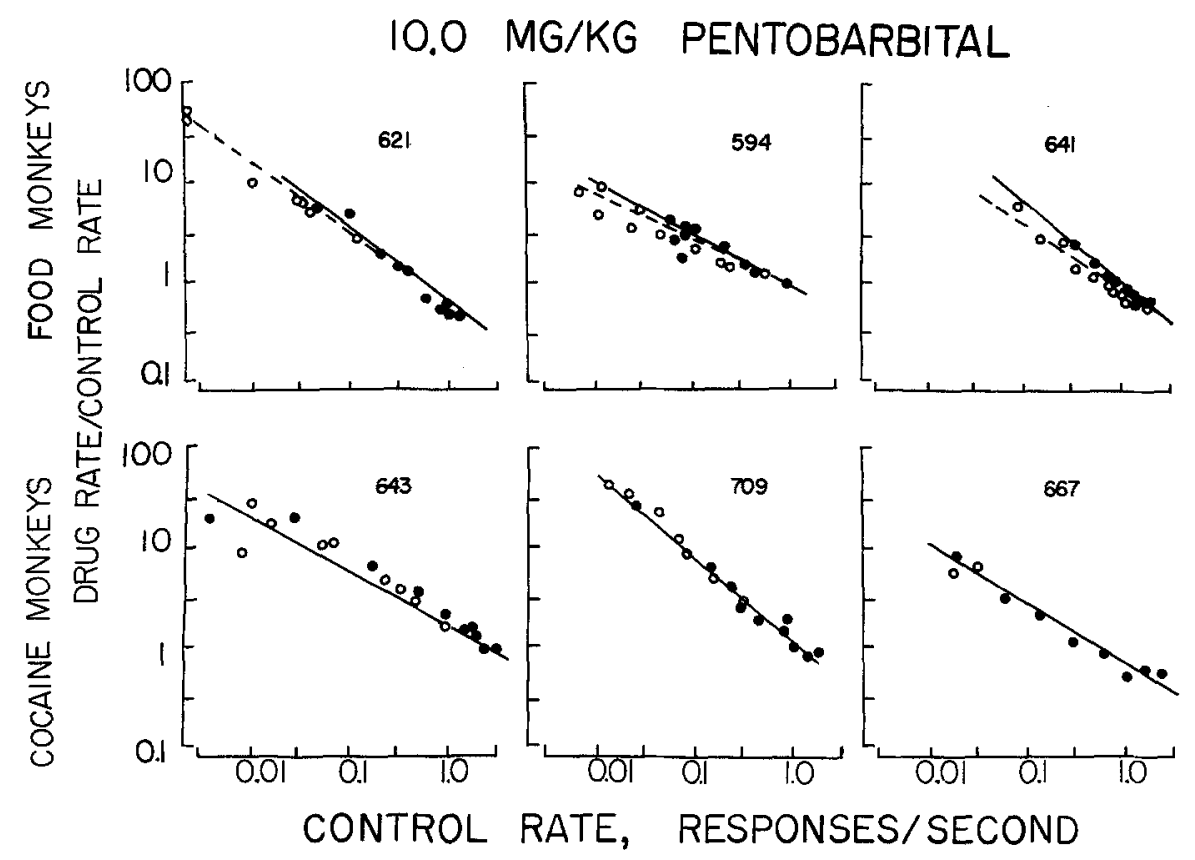

Fig. 4. Effects of $10.0 \mathrm{mg} / \mathrm{kg}$ pentobarbital (im) on reinforced and extinguished responding as a function of predrug (control) response rates for monkeys whose responding was maintained either by food (top row) or cocaine (bottom row). Refer to Fig. 2 for further details

The effects of $d$-amphetamine were in general agreement with those of cocaine though the effects of this drug were less consistent on food-reinforced responding. In monkey 641 , for example, $d$-amphetamine produced changes in local response rates that resulted in regression lines with large positive slopes (see Fig. 3); thus, the average slopes for the three food-reinforced monkeys (Table 2) varied unsystematically with dose.

\section{Discussion}

The effects of several drugs on operant behavior under a variety of conditions and in different species of animals have been shown to depend on the ongoing rate of responding (Kelleher and Morse, 1968; McMillan, 1973; Byrd, 1974). An analysis of the effects of cocaine, $d$-amphetamine, and pentobarbital on local rates of responding in this experiment revealed that these drugs typically increased low rates of responding, while higher rates were increased less or decreased. This ratedependent relationship generally held whether cocaine or food served as the reinforcer.

While the ability of barbiturates to affect operant responding in a. rate-dependent manner is welldocumented (e.g., Dews, 1964; McMillan, 1973), the effects of pentobarbital on overall response rates can be markedly different when different reinforcers maintain behavior (e.g., Barrett, 1976). In the present study, the effects of pentobarbital were independent of the type of reinforcer (i.e., food or cocaine) maintaining behavior. In addition, matched rates of reinforced and extinguished responding were altered comparably by pentobarbital.

Wilson and Schuster (1973) have reported that pentobarbital only suppresses very low rates of responding (four to five responses/h) maintained under a continuous reinforcement schedule of $200 \mu \mathrm{g} / \mathrm{kg}$ injections of cocaine. In the present experiment, however, pentobarbital markedly increased low rates of responding that occurred at the beginning of FI maintained by injections of $30 \mu \mathrm{g} / \mathrm{kg}$ cocaine. Pentobarbital's effects on responding maintained by injections of cocaine may depend on the dose and schedule of cocaine reinforcement, as well as the rate and pattern of ongoing behavior.

The more or less complete initial suppression of responding produced by cocaine in the present study was similar to that which has been reported in rats under a FR schedule of water presentation (MacPhail and Seiden, 1975) and in squirrel monkeys under FR and second-order schedules of food presentation (Gonzalez and Goldberg, 1977). The initial suppression and the subsequent rate increases caused by cocaine in the present experiment were comparable for behavior maintained by injections of cocaine and responding maintained by food presentations. Moreover, when local rates of responding were considered, the effects of cocaine on reinforced responding and responding during extinction were similar. 
Table 2. Average slopes and correlation coefficients $(r)$ of the regression lines and average response rates after drug injection $(y)$ as a ratio of the control rate when the control rate $(x)$ was 1 response/s. Data are means determined from one or more observations in three animals, except where noted. Ninety-five percent confidence limits of the means are given in parentheses ${ }^{a}$

\begin{tabular}{|c|c|c|c|c|c|c|c|}
\hline \multirow[t]{2}{*}{ Drug } & \multirow{2}{*}{$\begin{array}{l}\text { Dose } \\
\mathrm{mg} / \mathrm{kg}\end{array}$} & \multicolumn{3}{|l|}{ Food-reinforced } & \multicolumn{3}{|c|}{ Cocaine-reinforced } \\
\hline & & $\begin{array}{l}\text { Slope } \\
\text { degrees }\end{array}$ & $\begin{array}{l}y \text { value as a } \\
\text { ratio of } x \text {, when } \\
x=1 \text { response } / \mathrm{s}\end{array}$ & $r$ & $\begin{array}{l}\text { Slope } \\
\text { degrees }\end{array}$ & $\begin{array}{l}y \text { value as a } \\
\text { ratio of } x \text {, when } \\
x=1 \text { response } / \mathrm{s}\end{array}$ & $r$ \\
\hline \multirow[t]{4}{*}{ Pentobarbital } & 3.2 & $\begin{array}{l}-8 \\
(-15 \text { to }-1)\end{array}$ & $\begin{array}{l}1.15 \\
(0.93 \text { to } 1.37)\end{array}$ & 0.60 & $\begin{array}{l}-16 \\
(-24 \text { to }-8)\end{array}$ & $\begin{array}{l}1.37 \\
(1.27 \text { to } 1.47)\end{array}$ & 0.87 \\
\hline & 5.6 & $\begin{array}{l}-19 \\
(-23 \text { to }-15)\end{array}$ & $\begin{array}{l}1.28 \\
(0.91 \text { to } 1.65)\end{array}$ & 0.85 & $\begin{array}{l}-25 \\
(-28 \text { to }-22)\end{array}$ & $\begin{array}{l}1.60 \\
(1.25 \text { to } 1.95)\end{array}$ & 0.98 \\
\hline & 10.0 & $\begin{array}{l}-34 \\
(-39 \text { to }-29)\end{array}$ & $\begin{array}{l}0.84 \\
(0.64 \text { to } 1.04)\end{array}$ & 0.95 & $\begin{array}{l}-31 \\
(-36 \text { to }-26)\end{array}$ & $\begin{array}{l}1.14 \\
(0.65 \text { to } 1.63)\end{array}$ & 0.97 \\
\hline & 17.8 & $\begin{array}{l}-41 \\
(-53 \text { to }-29)\end{array}$ & $\begin{array}{l}0.10 \\
(0.04 \text { to } 0.16)\end{array}$ & 0.91 & $\begin{array}{l}-35 \\
(-45 \text { to }-25)\end{array}$ & $\begin{array}{l}0.16 \\
(0.00 \text { to } 0.34)\end{array}$ & 0.86 \\
\hline \multirow[t]{5}{*}{ Cocaine } & 0.1 & $\begin{array}{l}-7 \\
(-11 \text { to }-3)\end{array}$ & $\begin{array}{l}0.96 \\
(0.84 \text { to } 1.08)\end{array}$ & 0.49 & $\begin{array}{l}0 \\
(-12 \text { to } 12)\end{array}$ & $\begin{array}{l}1.46 \\
(1.36 \text { to } 1.56)\end{array}$ & 0.66 \\
\hline & 0.3 & $\begin{array}{l}-4 \\
(-19 \text { to } 11)\end{array}$ & $\begin{array}{l}0.90 \\
(0.59 \text { to } 1.21)\end{array}$ & 0.77 & $\begin{array}{l}-17 \\
(-22 \text { to }-12)\end{array}$ & $\begin{array}{l}1.25 \\
(0.74 \text { to } 1.76)\end{array}$ & 0.86 \\
\hline & 1.0 & $\begin{array}{l}-21 \\
(-42 \text { to } 0)\end{array}$ & $\begin{array}{l}0.67 \\
(0.43 \text { to } 0.91)\end{array}$ & 0.80 & $\begin{array}{l}-27 \\
(-32 \text { to }-22)\end{array}$ & $\begin{array}{l}0.98 \\
(0.55 \text { to } 1.41)\end{array}$ & 0.95 \\
\hline & 3.2 & $\begin{array}{l}-39^{b} \\
(-41 \text { to }-37)\end{array}$ & $\begin{array}{l}0.57^{\mathrm{b}} \\
(0.12 \text { to } 1.02)\end{array}$ & $0.95^{\mathrm{b}}$ & $\begin{array}{l}-26 \\
(-28 \text { to }-24)\end{array}$ & $\begin{array}{l}0.66 \\
(0.37 \text { to } 0.95)\end{array}$ & 0.76 \\
\hline & 5.6 & $\begin{array}{l}-32^{\mathrm{b}} \\
(-44 \text { to }-20)\end{array}$ & $\begin{array}{l}0.58^{b} \\
(0.27 \text { to } 0.89)\end{array}$ & $0.96^{\mathrm{b}}$ & $\begin{array}{l}-36^{b} \\
(-41 \text { to }-31)\end{array}$ & $\begin{array}{l}0.51^{\mathrm{b}} \\
(0.16 \text { to } 0.86)\end{array}$ & $0.99^{\mathrm{b}}$ \\
\hline \multirow[t]{3}{*}{$d$-Amphetamine } & 0.03 & $\begin{array}{l}-7 \\
(-10 \text { to }-4)\end{array}$ & $\begin{array}{l}1.13 \\
(0.97 \text { to } 1.29)\end{array}$ & 0.64 & $\begin{array}{l}-6 \\
(-11 \text { to }-1)\end{array}$ & $\begin{array}{l}1.24 \\
(1.00 \text { to } 1.48)\end{array}$ & 0.37 \\
\hline & 0.1 & $\begin{array}{l}19 \\
(-18 \text { to } 56)\end{array}$ & $\begin{array}{l}0.81 \\
(0.30 \text { to } 1.32)\end{array}$ & 0.77 & $\begin{array}{l}-12 \\
(-16 \text { to }-8)\end{array}$ & $\begin{array}{l}1.06 \\
(0.79 \text { to } 1.33)\end{array}$ & 0.93 \\
\hline & 0.3 & $\begin{array}{l}10 \\
(-34 \text { to } 54)\end{array}$ & $\begin{array}{l}0.40 \\
(0.15 \text { to } 0.65)\end{array}$ & 0.66 & $\begin{array}{l}-14 \\
(-28 \text { to } 0)\end{array}$ & $\begin{array}{l}0.65 \\
(0.22 \text { to } 1.08)\end{array}$ & 0.85 \\
\hline
\end{tabular}

a Data in this table were derived from individual regression lines such as those in Fig. 2, 3, and 4. Only data from the reinforcement component of the schedule were tabulated, since in many instances too few extinction data points (local rates) existed to allow a grouped comparison of doserelated changes of regression lines in the extinction component

b Based on observations in two animals

In squirrel monkeys, under a second-order schedule of food presentation, cocaine also produces an initial dose-related suppression of responding which is followed by responding at rates higher than control. However, compared to the overall effects produced by cocaine in the reinforcement components of the present experiment (Fig. 1), Gonzalez and Goldberg (1977) reported substantial overall response-rate increases in food-maintained responding. The relative lack of an overall response-rate increase in reinforced responding in the present experiment reflects to some extent the relative magnitude and duration of the suppression caused by cocaine compared to the subsequent increases in response rate that the drug produces (see Gonzalez and Goldberg, 1977).

Johanson (1978) reported that the psychomotor stimulants cocaine, $d$-amphetamine, and diethylpropion decreased food-maintained $\mathrm{FR}$ responding in rhesus monkeys at doses that had little effect on or increased comparable rates of shock avoidance. In addition, cocaine, and in one animal $d$-amphetamine and diethylpropion, produced a dose-related suppression of both differential reinforcement of low rates (DRL) and high FR rates of food-reinforced responding (Johanson, 1978). These findings are clearly different from the effects of psychomotor stimulants that have been reported in squirrel monkeys under FI or multiple FI, FR schedules of reinforcement. In these studies, cocaine and $d$-amphetamine produced comparable effects on responding maintained by food presentation and either shock avoidance, stimulus-shock termination, or shock presentations (Kelleher and Morse, 1964; McKearney, 1974; Barrett, 1976; Spealman et al., 1977). Furthermore, psychomotor stimulants tend to increase low rates of FI responding in several species at doses that suppress higher FI and FR rates of responding (e.g., Kelleher and Morse, 1964; McMillan, 1973; Byrd, 1973; Heffner et al., 1974). Since the effects of cocaine in the present experiment were largely rate-dependent and 
similar to the effects of the drug that have been reported in other species under comparable schedules of reinforcement (Barrett, 1976; Spealman et al., 1977), the relative independence of cocaine's effects on the baseline rate of responding in rhesus monkeys reported by Johanson (1978) was probably not related to the species of the subject used.

Amphetamine has been shown to cause ratedependent changes in operant responding in rats (Clark and Steele, 1966; Heffner et al., 1974), pigeons (McMillan, 1973), squirrel monkeys (McKearney, 1974), and chimpanzees (Byrd, 1973). In some cases, amphetamine's effects appear to be relatively independent of the nature of the reinforcing stimulus (Kelleher and Morse, 1964; Cook and Catania, 1964). For example, McKearney (1974) has shown that the effects of $d$-amphetamine are comparable whether responding is maintained by food or electric shock presentations. In the present experiment, $d$-amphetamine also produced effects that were largely independent of the nature of the reinforcing event; however, in some animals, amphetamine's effects could not be described simply as rate-dependent. For example, $0.3 \mathrm{mg} / \mathrm{kg}$ $d$-amphetamine completely suppressed the already low rates of responding during extinction in monkey 709 , as well as the low rates of responding during both components of the schedule in monkey 641 . That is, these low rates of responding were not elevated as might be predicted based solely on a rate-dependent analysis (Fig. 3). While the effects of amphetamines can depend upon control rates of responding under a variety of conditions, a few exceptions to this effect exist. For example, amphetamine has little tendency to increase very low control rates of responding when responding has had no programmed consequences (Verhave, 1958). It is not clear how this or other exceptions are related to the intersubject variability that existed in amphetamine's effect on matched rates of reinforced and extinguished responding in this experiment. Johanson (1978) has also reported individual variability in the effects of $d$-amphetamine on low rates of responding in rhesus monkeys. In one animal, $d$ amphetamine produced large increases in low rates of DRL responding, while the drug only produced response-rate decreases in a second animal.

The general absence of differential effects of cocaine, amphetamine, and pentobarbital on behavior maintained by food or cocaine in this experiment clearly suggests that such drugs can affect operant responding under some conditions in a manner that depends more critically on the ongoing rate and pattern of responding than on the nature of these maintaining events. It is entirely conceivable that responding maintained by larger doses of cocaine which have direct or rate-limiting effects on responding might interact more importantly with drug pretreatments. Nevertheless, the relative independence of drug effects on responding maintained by different reinforcers (i.e., food or cocaine) in the present experiment suggests that previous demonstrations of changes in psychomotor stimulantreinforced responding following pretreatments with various pharmacological agents (Wilson and Schuster, 1973; Pickens et al., 1968) might be attributable to the ability of these drugs to modify ongoing behavior in addition to or rather than their ability to substitute for or interact with the reinforcing effects of the drug reinforcer (Wilson and Schuster, 1973).

Acknowledgements. This research was supported by USPHS Grants DA00154 and DA01540, and was presented in part at the meetings of the Federation of American Societies for Experimental Biology, Atlantic City, N.J., April, 1975 (Herling et al., 1975). Seymore Herling was supported as a predoctoral fellow by the Alcohol and Drug Addiction Research Foundation, Ontario, Canada. The authors wish to express their appreciation to Isabel Herling for her assistance in the preparation of this manuscript.

\section{References}

Barrett, J. E.: Effects of alcohol, chlordiazepoxide, cocaine, and pentobarbital on responding maintained under fixed-interval schedules of food or shock presentation. J. Pharmacol. Exp. Ther. 196, 605-615 (1976)

Byrd, L. D.: Effects of $d$-amphetamine on schedule-controlled key pressing and drinking in the chimpanzee. J. Pharmacol. Exp. Ther. 185, 633-641 (1973)

Byrd, L. D.: Modification of the effects of chlorpromazine on behavior in the chimpanzee. J. Pharmacol. Exp. Ther. 189, 2432 (1974)

Clark, R. C., Steele, B. J.: Effects of $d$-amphetamine on performances under a multiple schedule in the rat. Psychopharmacologia (Berl.) 9, 157-169 (1966)

Cook, L., Catania, A. C.: Effects of drugs on avoidance and escape behavior. Fed. Proc. 23, $818-835$ (1964)

Davis, W. M., Smith, S. G.: Alpha-methyltyrosine to prevent selfadministration of morphine and amphetamine. Curr. Ther. Res. Clin. Exp. 14, 814-818 (1972)

Dews, P. B.: A behavioral effect of amobarbital. Naunyn Schmiedebergs Arch. Pharmacol. 248, 296-307 (1964)

Gill, C. A., Holz, W. C., Zirkle, C. L., Hill, H.: Pharmacological modification of cocaine and apomorphine self-administration in the squirrel monkey. In: Neuro-psychopharmacology: Proceedings of the tenth congress of the collegium internationale neuropsychopharmacologium, V.2, P. Deniker, C. Radouco-Thomas, A. Villeneuve, eds., pp. 1477-1484. Oxford: Pergamon 1978

Goldberg, S. R.: Comparable behavior maintained under fixed-ratio and second-order schedules of food presentation, cocaine injection or $d$-amphetamine injection in the squirrel monkey. J. Pharmacol. Exp. Ther. 186, 18-30 (1973)

Goldberg, S. R., Gonzalez, F. A.: Effects of propranolol on behavior maintained under fixed-ratio schedules of cocaine injection or food presentation in squirrel monkeys. J. Pharmacol. Exp. Ther. 198, 626-634 (1976)

Gonzalez, F. A., Goldberg, S. R.: Effects of cocaine and $d$ amphetamine on behavior maintained under various schedules of food presentation in squirrel monkeys. J. Pharmacol. Exp. Ther. 201, 33-43 (1977) 
Harris, R. A., Snell, D., Loh, H. H.: Effects of $d$-amphetamine, monomethoxy-amphetamines and hallucinogens on schedulecontrolled behavior. J. Pharmacol. Exp. Ther. 204, 103-117 (1978)

Heffner, T. G., Drawbaugh, R. B., Zigmond, M. J. : Amphetamine and operant behavior: Relationship between drug effect and control response rate. J. Comp. Physiol. Psychol. 86, 1031 -1043 (1974)

Herling, S., Downs, D. A., Woods, J. H.: Rate-dependent effects of drugs on food- and cocaine-reinforced lever-press responding in rhesus monkeys. Fed. Proc. 34, 765 (1975)

Johanson, C. E.: Effects of intravenous cocaine, diethylpropion, $d$-amphetamine, and perphenazine on responding maintained by food delivery and shock avoidance in rhesus monkeys. $\mathrm{J}$. Pharmacol. Exp. Ther. 204, 118-129 (1978)

Kelleher, R. T.: Conditioned reinforcement in second-order schedules. J. Exp. Anal. Behav. 9, $475-485$ (1966)

Kelleher, R. T., Morse, W. H.: Escape behavior and punished behavior. Fed. Proc. 23, 808-817 (1964)

Kelleher, R. T., Morse, W. H.: Determinants of the specificity of behavioral effects of drugs. Ergeb. Physiol. Biol. Chem. Exp. Pharmakol. 60, 1-56 (1968)

Leander, J. D.: Rate-dependent effects of drugs. Effects of some major tranquilizers on multiple fixed-ratio, fixed-interval schedule performances. J. Pharmacol. Exp. Ther. 193, 689-700 (1975)

MacPhail, R. C., Seiden, L. R.: Time course for the effects of cocaine on fixed-ratio water-reinforced responding in rats. Psychopharmacologia (BerI.) 44, 1-4 (1975)

McKearney, J. W.: Effects of $d$-amphetamine, morphine, and chlorpromazine on responding under fixed-interval schedules of food presentation or electric shock presentation. J. Pharmacol. Exp. Ther. 190, 141-153 (1974)

McKearney, J. W., Barrett, J. E.: Schedule-controlled behavior and the effects of drugs. In: Contemporary research in behavioral pharmacology, D. E. Blackman, D. J. Sanger, eds., pp. 1-68. New York: Plenum 1978

McMillan, D. E.: Drugs and punished responding. Rate-dependent effects under multiple schedules. J. Exp. Anal. Behav. 19, 133145 (1973)

Pickens, R., Meisch, R., Dougherty, J.: Chemical interactions in methamphetamine reinforcement. Psychol. Rep. 23, 1267-1270 (1968)

Spealman, R. D., Goldberg, S. R., Kelleher, R. T., Goldberg, D. M., Charlton, J. P.: Some effects of cocaine and two cocaine analogs on schedule-controlled behavior of squirrel monkeys. J. Pharmacol. Exp. Ther. 202, 500 - 509 (1977)

Verhave, T.: The effect of methamphetamine on operant level and avoidance behavior. J. Exp. Anal. Behav. 1, 207-219 (1958)

Wilson, M. C., Schuster, C. R.: The effects of chlorpromazine on psychomotor stimulant self-administration in the Rhesus monkey. Psychopharmacologia (Berl.) 26, 115-126 (1972)

Wilson, M. C., Schuster, C. R.: The effects of stimulants and depressants on cocaine self-administration behavior in the Rhesus monkey. Psychopharmacologia (Berl.) 31, 291-304 (1973)

Woods, J. H., Herling, S., Winger, G.: Chlorpromazine- and haloperidol-induced changes in some behavioral effects of cocaine and amphetamine. In: Neuro-psychopharmacology: Proceedings of the tenth congress of the collegium internationale neuro-psychopharmacologicum, V. 2, P. Deniker, C. Radouco-Thomas, A. Villeneuve, eds., pp. 1485-1502. Oxford: Pergamon 1978

Yokel, R. A., Wise, R. A.: Attenuation of intravenous amphetamine reinforcement by central dopamine blockade in rats. Psychopharmacology 48, 311-318 (1976)

Received August 5, 1978; Final version March 20, 1979 